\title{
An in vitro study, evaluating the effect of sunitinib and/or lapatinib on two glioma cell lines.
}

Efstathia Giannopoulou, PhD; Konstantinos Dimitropoulos, MD; Andreas A. Argyriou,

MD, PhD; Angelos K. Koutras, MD, PhD; Fotinos Dimitrakopoulos, MD and Haralabos P. Kalofonos, MD, PhD.

Clinical Oncology Laboratory, Division of Oncology, Department of Medicine, University Hospital of Patras, Patras Medical School, Greece

Running title: effect of sunitinib and/or lapatinib on glioma cells.

Address for Correspondence:

H.P. Kalofonos M.D., Ph.D.

Division of Oncology, Department of Medicine

University Hospital of Patras,

Rion, 26504, Greece

Tel: +30-2610-999535

Fax: +30-2610-994645

E-mail: kalofon@med.upatras.gr 
Aim: We sought to assess the effect of sunitinib and lapatinib applied either alone or in combination, on U87 and M059K glioma cells.

Methods: Both cell lines were cultured as recommended by the manufacturer. Sunitinib and lapatinib were applied, either separately or in combination, in the cultured cells after cell attachment at doses of $10 \mathrm{nM}, 100 \mathrm{nM}, 1 \mu \mathrm{M}$ and $10 \mu \mathrm{M}$. To determine whether the agents affect the proliferation of glioma cells, the 3-[4,5-dimethylthiazol-2-yl]-2,5 dimethyltetrazolium bromide assay was used. Apoptosis was detected using annexin V/propidium iodide detection assay, migration assay was performed in 24-well microchemotaxis chambers. The release of MMPs into the culture medium of U87 and M059K cells was measured by zymography.

Results: Both agents, administered either alone or in combination, decreased cell proliferation in a dose-dependent manner $48 \mathrm{~h}$ after their application in both cell lines. The inhibition of their combination was statistically different than the inhibition of each agent alone. Apoptosis was increased and migration of U87 and M059K cells was inhibited either by each agent alone or their combination. MMPs levels remained unaffected by the application of both agents in U87 cells. However, MMP-9 and MMP-2 levels were decreased $48 \mathrm{~h}$ after treatment of M059K cells with sunitinib either alone or in combination with lapatinib.

Conclusion: Sunitinib and/or lapatinib appear to exhibit significant effects on proliferation, apoptosis and migration of glioma cells. When applied alone, sunitinib appears to be a more potent inhibitor than lapatinib.

\section{Keywords}

Lapatinib, sunitinib, malignant glioma, proliferation, apoptosis, migration, MMPs. 


\section{Introduction}

Malignant gliomas (MGs), including glioblastomas (GBMs) and anaplastic astrocytomas (AAs) are the most common and aggressive primary brain tumors. Despite treatment advances, the outcome of patients with MG remains dismal [1]. Recent advances, mostly in the thorough understanding of the complex molecular pathogenesis of MGs, have led to the arousal of rational development of molecularly targeted treatment options $[1,2]$. Currently, monoclonal antibodies (MAbs) targeting angiogenesis, several multitargeted kinase inhibitors and combination of single-targeted kinase inhibitors of ErbB family receptors have been tested in experimental models and clinical trials for their ability to establish future therapeutic directions in MGs [2].

Sunitinib (Sutent) is an oral, small-molecule, multi-targeted receptor TKI, including platelet-derived growth factor receptors (PDGFR) and vascular endothelial growth factor receptors [3]. Sunitinib exhibits potent antiangiogenic and antitumor activity, particularly evident in advanced renal cell carcinoma (RCC). The inhibitory effect of sunitinib has previously been shown in several RCC and gastrointestinal stromal malignant cell lines [4], as well as in breast [5] and neuroendocrine cancer cell lines [6]. To our knowledge, only one study has examined the inhibitory effect of sunitinib in glioma cell lines [7]. Additionally, sunitinib has also shown survival benefits against a subcutaneous glioma xenograft [8].

Lapatinib (Tykerb) is an ATP-competitive epidermal growth factor receptor (EGFR) and HER2/neu (ErbB-2) dual TKI. An important inhibitory effect of lapatinib has been demonstrated in certain cell lines, including human breast and prostate cancer $[9,10]$. 
To our knowledge, there is a lack of experimental studies in the literature on the inhibitory effect of lapatinib in MGs. However, with a great deal of evidence-based empirical expectations of benefits, an in vitro study of lapatinib in glioma cell lines appears to be justified.

Although the efficacy of each one of the TKIs combined with other conventional cytotoxic agents, such as sunitinib and lenalidomide plus low-dose metronomic cyclophosphamide [11] or lapatinib and tamoxifen [9] has been studied, little is currently known about the efficacy of the combination of these two TKIs. Additionally, considering the lack of studies directly comparing the effect of sunitinib versus lapatinib on human cancer cell lines, another issue that remains to be clarified is which of these agents is a more potent inhibitor when applied alone.

The aim of the current in vitro study was to assess the effect of sunitinib and lapatinib applied either alone or in combination on proliferation, apoptosis, migration and release of MMP-2 into the culture medium of U87 human glioblastoma cells.

\section{Materials and Methods}

\section{Cell culture and reagents}

The U87 and M059K glioblastoma cell lines were cultured in DMEM with $2 \mathrm{mM}$ L-glutamine and supplemented with $10 \%$ fetal bovine serum, $100 \mathrm{U} / \mathrm{ml}$ penicillinstreptomycin and $50 \mu \mathrm{g} / \mathrm{ml}$ gentamycin at $37^{\circ} \mathrm{C}, 5 \% \mathrm{CO}_{2}$ and $100 \%$ humidity. The tested agents were applied in cells at doses of $0 ; 0.01 ; 0.1 ; 1$ and $10 \mu \mathrm{M}$. Both agents were diluted 
in phosphate buffered saline $\mathrm{pH}$ 7.6 (PBS) with dimethyl sulfoxide (DMSO). The final concentration of in the culture medium was $0.5 \%$.

\section{Cell proliferation assay}

To determine whether the aforementioned agents affect the proliferation of U87 and M059K cells, the 3-[4,5-dimethylthiazol-2-yl]-2,5-dimethyltetrazolium bromide (MTT) assay was used, as previously described [12]. Proliferation assay was performed in serum free medium $48 \mathrm{~h}$ after the addition of the tested agents.

\section{Apoptosis assay}

Apoptosis was detected using annexin V/propidium iodide detection assay as previously described $[12,13]$. Tested agents were added in U87 and M059K cells as described above, 24 and $48 \mathrm{~h}$ later cells were analyzed by flow cytometry (EPICS-XL of Coulter) according to the manufacturer's instructions (rh Annexin V/FITC kit, Bender MedSystems). The experiments were performed in serum free medium.

\section{Migration assay}

Migration assays were performed as previously described [14], in 24-well microchemotaxis chambers (Costar, Avon, France), using uncoated polycarbonate membranes with $8 \mu \mathrm{m}$ pores. Briefly, U87 and M059K cells were harvested and resuspended at $3 \times 10^{4}$ cells $/ 0.1 \mathrm{ml}$ in serum free medium containing $0.25 \%$ bovine serum albumin. The bottom chamber was filled with $0.6 \mathrm{ml}$ of serum free medium with the tested agents. The upper chamber was loaded with $3 \times 10^{4}$ cells and incubated for $4 \mathrm{~h}$ at $37{ }^{\circ} \mathrm{C}$. After completion of the incubation, the filters were fixed with saline-buffered formalin and 
stained with $0.33 \%$ toluidine blue solution. The cells that migrated through the filter were quantified by counting the entire area of each filter, using a grid and a microscope at a $20 \mathrm{x}$ magnification.

\section{Zymography}

The release of MMP-9 and MMP-2 into the culture medium of U87 and M059K was measured by zymography as previously described [14]. In brief, U87 cells were plated in 24-well plates at a density of $3 \times 10^{4}$ cells per well in serum free medium. The cells were treated with the tested agents, as described above for the proliferation studies. At 24 and 48 $\mathrm{h}$ later, $50 \mu \mathrm{l}$ of the medium from each group were diluted with $2 \mathrm{x}$ Laemmli sample buffer without $\beta$-mercaptoethanol. Alternative, samples of M059K cells were concentrated at 12 fold prior the addition of Laemmli buffer. Protein concentration was detected using Bradford assay and equals amounts of total proteins were analysed. Samples from both cell lines were analyzed in $10 \%$ SDS-PAGE gels containing $0.1 \%$ gelatin. Following electrophoresis, gels were washed four times in $2.5 \%$ Triton-X 100 for 15 min at room temperature and incubated for $24 \mathrm{~h}$ at $37^{\circ} \mathrm{C}$ in developing buffer $(50 \mathrm{mM}$ Tris- $\mathrm{HCl} \mathrm{pH}$ 7.6, $200 \mathrm{mM} \mathrm{NaCl}$ and $10 \mathrm{mM} \mathrm{CaCl}_{2}$ ). The gels were stained with Coomassie Brilliant Blue $\mathrm{R}$

for $4 \mathrm{~h}$ at room temperature, de-stained in methanol acetic acid-water $(4.5: 1: 4.5 \mathrm{v} / \mathrm{v})$ for $2 \mathrm{~h}$ and photographed using a digital camera.

\section{Statistical analysis}

Differences between groups and controls were tested using the one way analysis of variance (ANOVA). Each experiment included at least triplicate measurements for each 
condition tested. All results are expressed as mean \pm SEM from at least three independent experiments.

\section{Results}

Effects on cell proliferation and apoptosis

Initially, we studied the effect of sunitinib and lapatinib in U87 and M059K cell proliferation. We found that both agents decreased cell proliferation in a dose dependent manner $48 \mathrm{~h}$ after their application in cells (Fig. $1 \mathrm{~A}$ and B). At $1 \mu \mathrm{M}$, sunitinib as well as lapatinib inhibited cell proliferation, without being toxic for cells. In U87 cells, the inhibitory effect was not statistically significant between agents (sunitinib vs lapatinib) and was reached at $15 \% \pm 2$ and $24 \% \pm 3$, respectively. However, in M059K cells, lapatinib was more effective than sunitinib. The inhibitory effect for sunitinib and lapatinib was $26 \% \pm 3$ and $42 \% \pm 5$, respectively. The difference was statistically significant and p value was $<0.05$. In contrast, at $10 \mu \mathrm{M}$ both agents were toxic for both cell lines (Fig. 1A and B).

The inhibitory effect of the combination of sunitinib and lapatinib was also studied. We found that at $1 \mu \mathrm{M}$, the inhibition was reached at $47 \% \pm 7$ and $87 \% \pm 5$ in $\mathrm{U} 87$ and M059K cells, respectively (Fig.1C and D). The inhibition of agent's combination was statistically different than the inhibition of each agent alone. In U87 cells, the p values was $<0.001$ and $<0.01$ for sunitinib and lapatinib, respectively, compared to their combination. Moreover, in M059K cells, the $\mathrm{p}$ values were $<0.001$ and $<0.001$ for sunitinib and lapatinib, respectively. According to the formula of Fischel et al [15], the effect of agent's 
combination is synergistic. The combination of sunitinib and lapatinib at $10 \mu \mathrm{M}$ was toxic for cells since the number of cells was lower than cells were used for the initiation of proliferation assay (Fig. 1C and D).

Furthermore, we studied the effect of sunitinib and lapatinib in cell apoptosis. We found that 24 and $48 \mathrm{~h}$ after agent's application, apoptosis was increased either by each agent alone or their combination in both cell lines (Fig. 2). The percentage of apoptotic cells in untreated U87 cells was $12 \% \pm 2$ and $7 \% \pm 2$ at 24 and $48 \mathrm{~h}$ respectively, after the addition of sunitinib $1 \mu \mathrm{M}$ the percentages were elevated to $87 \% \pm 2$ and $65 \% \pm 11$, respectively, while lapatinib $1 \mu \mathrm{M}$ alone increased the apoptotic cells to $32 \% \pm 1$ and $20 \%$ \pm 0.5 , respectively. The combination of sunitinib and lapatinib at $1 \mu \mathrm{M}$ increased the percentage of apoptotic cells up to $99 \% \pm 0.1$ and $92 \% \pm 2$ at 24 and $48 \mathrm{~h}$ after the addition of agents (Fig. 2A). In M059K cells, the percentages of apoptotic cells were $21 \% \pm 7$ and $19 \% \pm 2$ at 24 and 48 h, respectively. Sunitinib increased the percentages up to $98 \% \pm 0.5$ and $80 \% \pm 10$ at the same time points. Lapatinib, did not affect the percentage of apoptotic cells at $24 \mathrm{~h}(26 \% \pm 0.6)$, however the percentage of apoptotic cells was increased up to $36 \% \pm 4$ at $48 \mathrm{~h}$. The combination of agents increased the percentage of apoptotic cells up to $83 \% \pm 10$ and $79 \% \pm 6$, at 24 and 48 h, respectively (Fig. $2 B$ ).

\section{Effects on U87 migration capacity}

We found that each agent alone as also their combination inhibited the migration of U87 (Fig. 3A) and M059K (Fig. 3B) cells. We found that sunitinib and lapatinib at $1 \mu \mathrm{M}$ reduced migration of $U 87$ cells at $45 \% \pm 11$ and $21 \% \pm 13$, respectively, while their combination caused a reduction in migration up to $42 \% \pm 3$. In M059K cells, both $1 \mu \mathrm{M}$ 
sunitinib and $1 \mu \mathrm{M}$ lapatinib reduced cell migration at $51 \% \pm 15$ and $28 \% \pm 9$, respectively. Their combination reduced cell migration at $62 \% \pm 5$.

Effects on secretion of MMPs

U87 and M059K cells were treated with sunitinib $1 \mu \mathrm{M}$ or lapatinib $1 \mu \mathrm{M}$ or their combination. Twenty four and $48 \mathrm{~h}$ later we studied the secretion of MMPs in culture medium. We found that neither each agent alone nor their combination alter MMP-9 and MMP-2 levels in U87 as shown in figure 4 compared to untreated cells. However, sunitinib decreased MMP-9 and MMP-2 levels, $48 \mathrm{~h}$ after its application to M059K cells alone or in combination with lapatinib.

\section{Discussion}

Multiple or compensatory pathways are involved in the molecular pathogenesis of MGs, whereas multiple receptor tyrosine kinases (RTKs) are coactivated in MGs [16]. MGs are highly dependent on angiogenesis for growth, and therefore, the application of antiangiogenic molecularly targeted treatment strategies with MAbs or TKIs appears to have a solid rationale [17].

To date, a limited number of publications have supported the hypothesis that small TKIs may cross the blood-brain barrier [1]. In any case, the antitumor and antiangiogenic potential of these agents is not widely tested either in experimental or in clinical models of MGs. We therefore tested the antitumor effect of two multi-targeted receptor TKIs, applied 
alone or in combination on U87 and M059K cell lines, by evaluating the changes in cell proliferation, apoptosis, migration and MMPs secretion.

Our main finding to emerge was that both sunitinib and lapatinib, when applied alone, decreased cell proliferation in a dose-dependent manner, increased apoptosis and inhibited the migration of both cell lines. This effect was even stronger when the combination of these two drugs was applied. However, when we applied sunitinib alone, we found that it exhibits a stronger antitumor effect compared to lapatinib in the culture medium of U87 and M059K.

Interestingly, no difference in MMPs secretion was detected by zymography analysis of U87 cells conditioned medium following either the application of sunitinib and lapatinib alone or their combination. Therefore, one could assume that the changes in glioma cell invasion may occur without being associated with the alterations in MMPs levels and this event could be potentially attributed to heparanase elevation [18]. Alternative, sunitinib and lapatinib [19] may decrease cells migration through decrease of phosphorylated FAK [7] without necessarily affecting MMPs secretion from U87 cells. This may imply that MMPs is an essential but not a sufficient factor contributing to migration ability of cells [20]. Downregulation of the status of cell surface AlfaVBeta3 integrin after drug application may also be implicated and due to that tumor cell surface recruited much less MMPs from surroundings. In contrast, both MMP-9 and MMP-2 levels were decreased after treatment of M059K cells with sunitinib either alone or in combination with lapatinib.

In this study, sunitinib exhibited in a dose-dependent manner a potent antitumor activity and this is primarily attributed to its ability to inhibit angiogenesis, targeting both 
VEGFRs and PDGFRs. Additionally, sunitinib may also be able to exert a direct antiproliferative effect on PDGFR-dependent glioma cells [21]. As mentioned earlier, another study previously investigated the inhibitory effect of sunitinib in human glioblastoma cell lines, and in agreement with our results, reached to the conclusion that sunitinib exhibited a potent antiangiogenic activity on U87MG cells. However, this effect was evident and limited to the application of high-dose $(10 \mu \mathrm{M})$ sunitinib, whereas this high concentration was non-toxic for cells [7]. In our study, the antitumor effect of both sunitinib and lapatinib was evident at $1 \mu \mathrm{M}$, without being toxic for cells, while in contrast to the de Boüard et al, [7] study both agents were toxic for U87 and M059K cells when applied at $10 \mu \mathrm{M}$. Differences in the nature of cells cultured could account for this discrepancy between results. We investigated the effect of sunitinib and/or lapatinib particular on U87 cells, whereas a different culture medium of U87MG cells was used in the de Boüard et al, study [7]. Additionally, although U87 cells are commercially available, it is possible to give dissimilar clones when cultured in different laboratories.

Although to a smaller extent compared to sunitinib, lapatinib affected U87 and M059K cells in a dose-dependent manner, due to its ability to target EGFR and HER2. However, human glioblastoma cells may be less sensitive to this molecule compared to sunitinib, because lapatinib seems less able to downregulate the phosphatidylinositol 3kinase (PI3-K)/Akt pathway, which is a critical pathway for glioma growth and invasion [22]. In any case, it should be mentioned that lapatinib is the first HER2-directed drug, which was validated in an in vivo preclinical model for activity against brain metastases of breast cancer [19]. 
The activation state of PI3K and mitogen-activated protein kinase pathways may be determined by the sum of multiple inputs, and multiple RTKs may be at the same time or sequentially employed by MGs cells to maintain signal flux. In such a case, effective MG therapy may require combination of drugs against different activated RTKs [23]. In our study and in line with the latter view, the combination of sunitinib and lapatinib exhibited a dual effect on cell proliferation, apoptosis and migration of U87 cells, which should be attributed to multiple targeting against EGFRs, HER2, VEGFRs and PDGFRs, resulting in the inhibition of angiogenesis and the downregulation of EGFR and HER-2 protein levels. In a similar manner, combination therapy of inhibitors of EGFR/VEGFR-2 (AEE788) and the mammalian target of rapamycin (RAD001) offered in another in vitro study improved glioblastoma tumor growth inhibition [24]. In all likelihood, our results advocate in favor of the view that the multiple-targeting treatment approaches using combined use of two different agents could be more effective than application of each agent alone.

In the current setting, we have examined the activity of sunitinib and/or lapatinib on a single cell line and one could mention that this represents a significant methodological limitation. We might acknowledge this limitation; however, the cell line that we have used (U87) ranks among the most widely used and well studied human glioblastoma cell lines.

In the clinical setting, although the role of sunitinib in advanced $\mathrm{RCC}$ has been evaluated through large prospective trials, the efficacy of the drug in patients with primary or secondary brain tumors has not been explored, since patients with cerebral lesions were excluded in those studies $[25,26]$. Interestingly, in line with the results of the current study, on the potent antitumor activity of sunitinib in glioma cells, is a clinical case report recently published by our group. In this report, monotherapy with sunitinib resulted in a 
considerable shrinkage of a solitary brain metastasis from RCC without manifestation of any serious adverse event or central nervous system toxicities [27]. On the other hand, the regimen consisting of lapatinib plus capecitabine in patients with HER-2 positive refractory advanced breast cancer has been found in a randomized trial superior than capecitabine alone in terms of less CNS progression [28].

To summarize, the application of sunitinib and/or lapatinib appears to exhibit significant effects on proliferation, apoptosis and migration of human glioblastoma cell lines. When applied alone, sunitinib has a more potent antitumor activity than lapatinib in cells. Multiple targeting as a result of the combined application of sunitinib and lapatinib improved the antitumor effect. Further in vitro studies are warranted to address this important issue. 


\section{References}

1. Argyriou AA, Antonacopoulou A, Iconomou G, Kalofonos HP (2009) Treatment options for malignant gliomas, emphasizing towards new molecularly targeted therapies. Crit Rev Oncol Hematol 69(3): 199-210.

2. Omuro AM, Faivre S, Raymond E (2007) Lessons learned in the development of targeted therapy for malignant gliomas. Mol Cancer Ther 6(7): 1909-19.

3. Polyzos A (2008) Activity of SU11248, a multitargeted inhibitor of vascular endothelial growth factor receptor and platelet-derived growth factor receptor, in patients with metastatic renal cell carcinoma and various other solid tumors. $\mathbf{J}$ Steroid Biochem Mol Biol 108(3-5): 261-6.

4. Adams VR, Leggas M (2007) Sunitinib malate for the treatment of metastatic renal cell carcinoma and gastrointestinal stromal tumors. Clin Ther 29(7): 1338-53.

5. Abrams TJ, Murray LJ, Pesenti E, Holway VW, Colombo T, Lee LB, Cherrington JM, Pryer NK (2003) Preclinical evaluation of the tyrosine kinase inhibitor 5U11248 as a single agent and in combination with "standard of care" therapeutic agents for the treatment of breast cancer. Mol Cancer Ther 2: 1011-1021.

6. Cuneo KC, Geng L, Fu A, Orton D, Hallahan DE, Chakravarthy AB (2008) SU11248 (sunitinib) sensitizes pancreatic cancer to the cytotoxic effects of ionizing radiation. Int J Radiat Oncol Biol Phys 71(3): 873-9.

7. de Boüard S, Herlin P, Christensen JG, Lemoisson E, Gauduchon P, Raymond E, Guillamo JS (2007) Antiangiogenic and anti-invasive effects of sunitinib on experimental human glioblastoma. Neuro Oncol 9(4): 412-23. 
8. Schueneman AJ, Himmelfarb E, Geng L, Tan J, Donnelly E, Mendel D, McMahon G, Hallahan DE (2003) SU11248 maintenance therapy prevents tumor regrowth after fractionated irradiation of murine tumor models. Cancer Res 63(14): 4009-16.

9. Chu I, Blackwell K, Chen S, Slingerland J (2005) The Dual ErbB1/ErbB2 Inhibitor, Lapatinib (LAPATINIB), cooperates with tamoxifen to inhibit both cell proliferation- and estrogen-dependent gene expression in antiestrogen-resistant breast cancer. Cancer Res 65: 18-25.

10. Gregory C, Whang YE, McCall W, Fei X, Liu Y, Ponguta LA, French FS, Wilson EM, Shelton H (2005) Heregulin-induced activation of HER2 and HER3 increases androgen receptor transactivation and CWR-R1 human recurrent prostate cancer cell growth. Clin Cancer Res 11: 1704-1712.

11. Blansfield JA, Caragacianu D, Alexander HR 3rd, Tangrea MA, Morita SY, Lorang $\mathrm{D}$, Schafer $\mathrm{P}$, et al. Combining agents that target the tumor microenvironment improves the efficacy of anticancer therapy. Clin Cancer Res. 2008; 14(1): 270-80.

12. Giannopoulou E, Papadimitriou E (2003) Amifostine has antiangiogenic properties in vitro by changing the redox status of human endothelial cells. Free Rad Res 37(11): 1191-1199.

13. Kuwada SK, Scaife CL, Kuang J, Li X, Wong RF, Florell SR, Coffey RJ, Gray PD (2004) Effects of trastuzumab on epidermal growth factor receptor-dependent andindependent human colon cancer cells. Int J Cancer 109: 291-301.

14. Giannopoulou E, Antonacopoulou A, Floratou K, Papavassiliou A, Kalofonos H. Dual targeting of EGFR and HER-2 in colon cancer cell lines. Cancer Chemother Pharmacol. Doi: 10.1007/s00280-008-0820-9. 
15. Fischel JL, Formento P, Milano G (2005) Epidermal growth factor receptor double targeting by a tyrosine kinase inhibitor (Iressa) and a monoclonal antibody (Cetuximab). Impact on cell growth and molecular factors. Br J Cancer 92(6): 10631068.

16. Sathornsumetee S, Reardon DA, Desjardins A, Quinn JA, Vredenburgh JJ, Rich JN (2007) Molecularly targeted therapy for malignant glioma. Cancer 110(1): 13-24.

17. Hanahan D, Folkman J (1996) Patterns and emerging mechanisms of the angiogenic switch during tumorigenesis. Cell 86(3): 353-64.

18. Zetser A, Bashenko Y, Miao HQ, Vlodavsky I, Ilan N (2003) Heparanase affects adhesive and tumorigenic potential of human glioma cells. Cancer Res 63(22): $7733-41$.

19. Gril B, Palmieri D, Bronder JL, Herring JM, Vega-Valle E, Feigenbaum L, Liewehr DJ, et al (2008) Effect of lapatinib on the outgrowth of metastatic breast cancer cells to the brain. J Natl Cancer Inst 100(15): 1092-103.

20. Xing W, Hamaguchi M (2007) Effects of SHIP-1 on MMP2 secretion and invasion of SR3Y1 cells, J Genet Genomics 34(4): 285-293.

21. Westermark B, Heldin CH, Nistér M (1995) Platelet-derived growth factor in human glioma. Glia 15(3): 257-63.

22. Mischel PS, Cloughesy TF (2003) Targeted molecular therapy of GBM. Brain Pathol 13(1): 52-61.

23. Stommel JM, Kimmelman AC, Ying H, et al (2007) Coactivation of receptor tyrosine kinases affects the response of tumor cells to targeted therapies. Science 318(5848): 287-90. 
24. Goudar RK, Shi Q, Hjelmeland MD, Keir ST, McLendon RE, Wikstrand CJ, Reese ED, et al (2005) Combination therapy of inhibitors of epidermal growth factor receptor/vascular endothelial growth factor receptor 2 (AEE788) and the mammalian target of rapamycin (RAD001) offers improved glioblastoma tumor growth inhibition. Mol Cancer Ther 4(1): 101-12.

25. Motzer RJ, Rini BI, Bukowski RM, et al (2006) Sunitinib in patients with metastatic renal cell carcinoma. JAMA 295: 2516-2524.

26. Motzer RJ, Hutson TE, Tomczak P, et al (2007) Sunitinib versus interferon alfa in metastatic renal-cell carcinoma. N Engl J Med 356: 115-124.

27. Koutras AK, Krikelis D, Alexandrou N, Starakis I, Kalofonos HP (2007) Brain metastasis in renal cell cancer responding to sunitinib. Anticancer Res 27(6C): 4255-7.

28. Geyer CE, Forster J, Lindquist D, et al. Lapatinib plus capecitabine for HER2positive advanced breast cancer (2006) N Engl J Med 355: 2733-2743. 


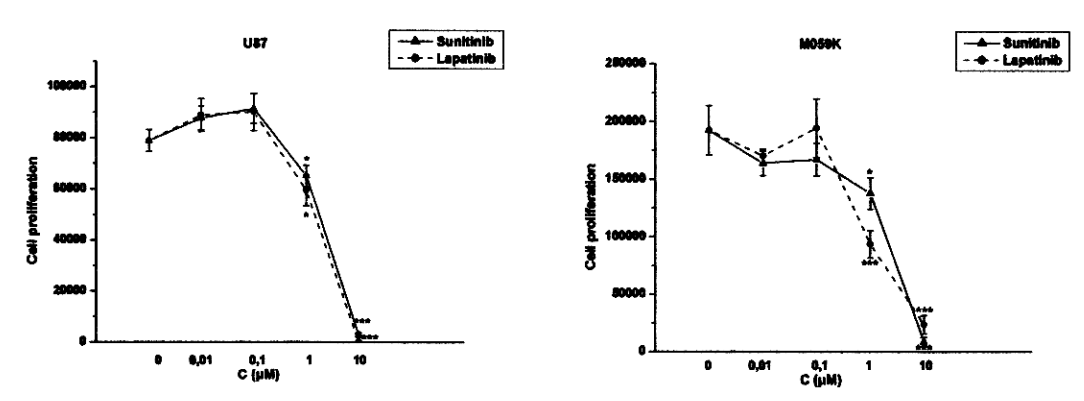

$\mathbf{A}$

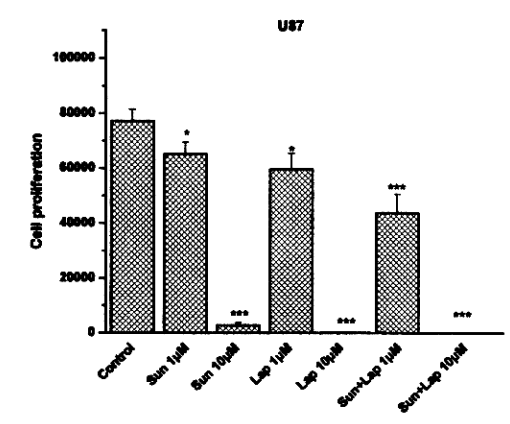

C
B

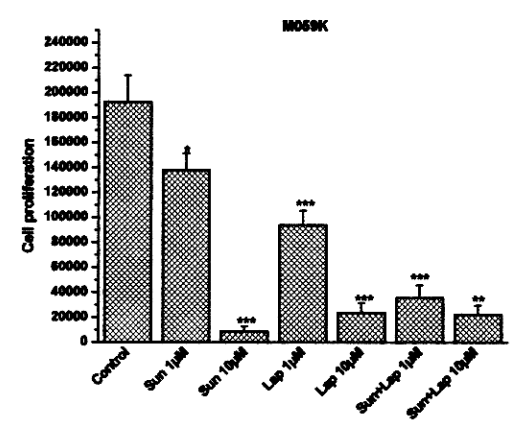

D

Figure 1: A, B) Different doses of sunitinib or lapatinib were applied on U87 and M059K cells, respectively. B) The combination of sunitinib and lapatinib inhibited U87 proliferation. Results are expressed as mean \pm SEM of the number of cells. Asterisks denote a statistically significant difference (unpaired $t$-test) compared to untreated cells. * $P<0.05, * * P<0.01$ and $* * * P<0.001$. 

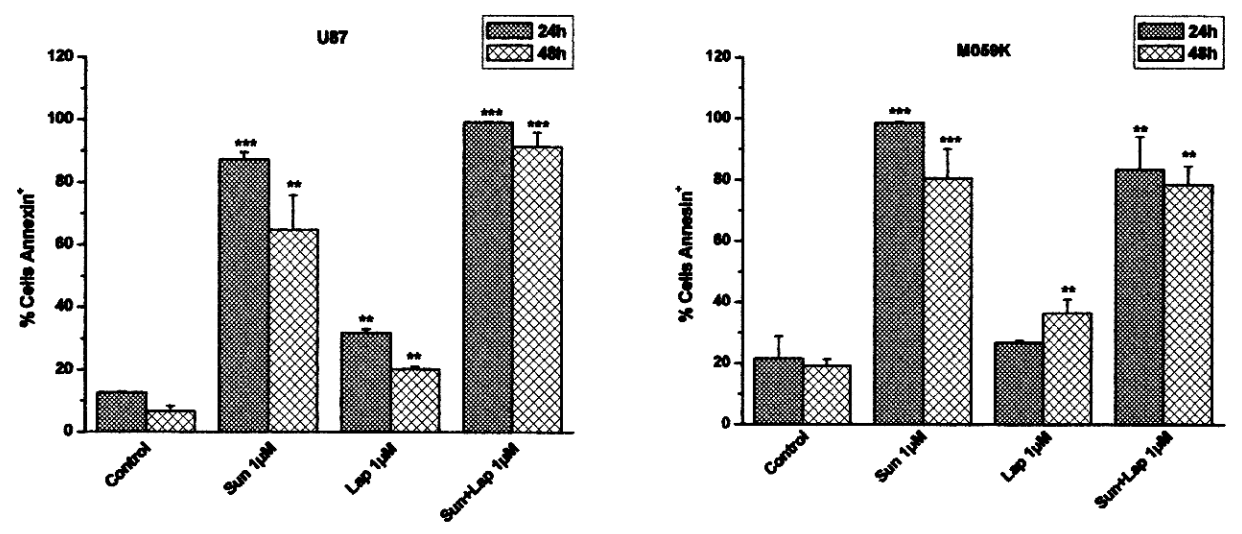

A

B

Figure 2: The effect of sunitinib and lapatinib on U87 (A) and M059K (B) apoptosis 24 and $48 \mathrm{~h}$ after treatment of cells with the tested agents. Results are expressed as the percentage of Annexin ${ }^{+}$cells \pm SEM. Asterisks denote a statistically significant difference (unpaired $t$-test) compared to untreated cells. Control: untreated U87/M059K cells, Sun 1 $\boldsymbol{\mu M}$ : U87/M059K cells treated with $1 \mu \mathrm{M}$ sunitinib, Lap $1 \boldsymbol{\mu M}$ : U87/M059K cells treated with $1 \mu \mathrm{M}$ lapatinib, S+L $\mathbf{1} \boldsymbol{\mu M}$ : U87/M059K cells treated with $1 \mu \mathrm{M}$ sunitinib and $1 \mu \mathrm{M}$ lapatinib. $* * P<0.01$ and $* * * \mathrm{P}<0.001$. 

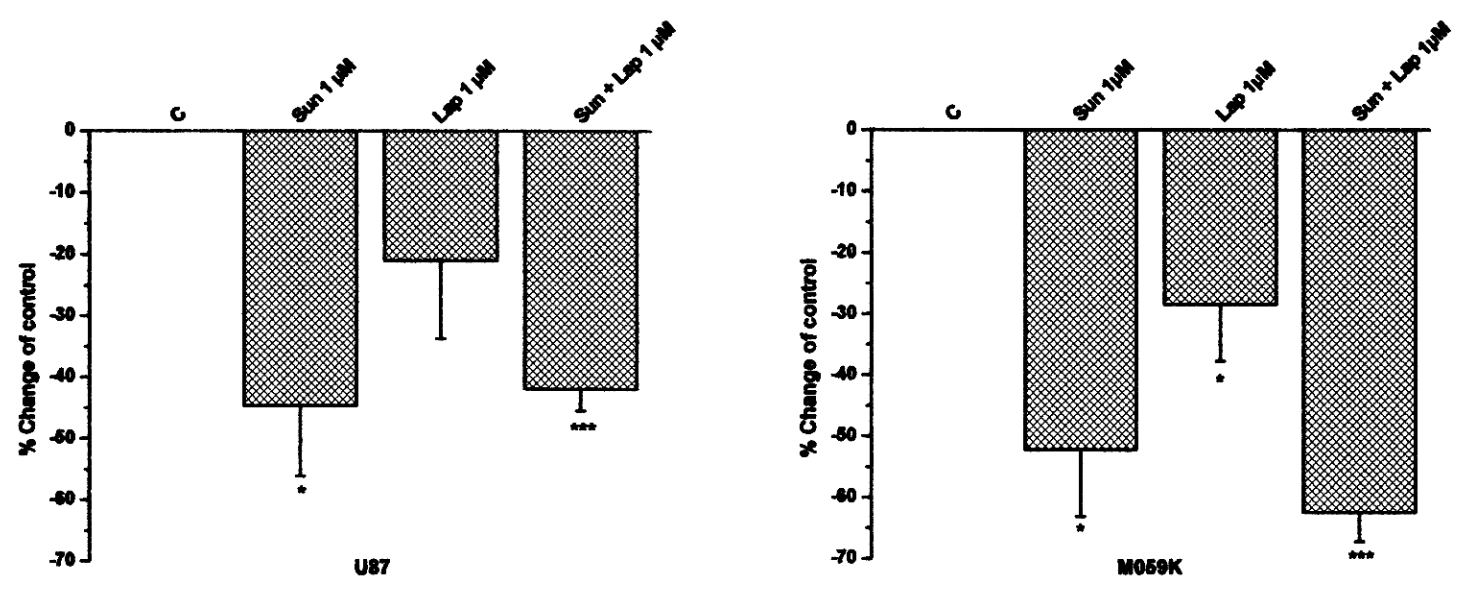

$\mathbf{A}$

B

Figure 3: The effect of sunitinib and lapatinib on U87 (A) and M059K (B) invasion capacity. Results are expressed as mean \pm SEM of the $\%$ change compared to the untreated cells. Asterisks denote a statistically significant difference (unpaired $t$-test) compared to untreated U87/M059K cells. C: untreated U87/M059K cells, Sun $1 \boldsymbol{\mu M}$ : U87/M059K cells treated with $1 \mu \mathrm{M}$ sunitinib, Lap $1 \boldsymbol{\mu M}$ : U87/M059K cells treated with $1 \mu \mathrm{M}$ lapatinib, Sun+Lap $1 \mu \mathrm{M}$ : U87/M059K cells treated with $1 \mu \mathrm{M}$ sunitinib and $1 \mu \mathrm{M}$ lapatinib. ${ }^{*} P<$ $0.05, * * P<0.01$ and $* * * \mathrm{P}<0.001$. 


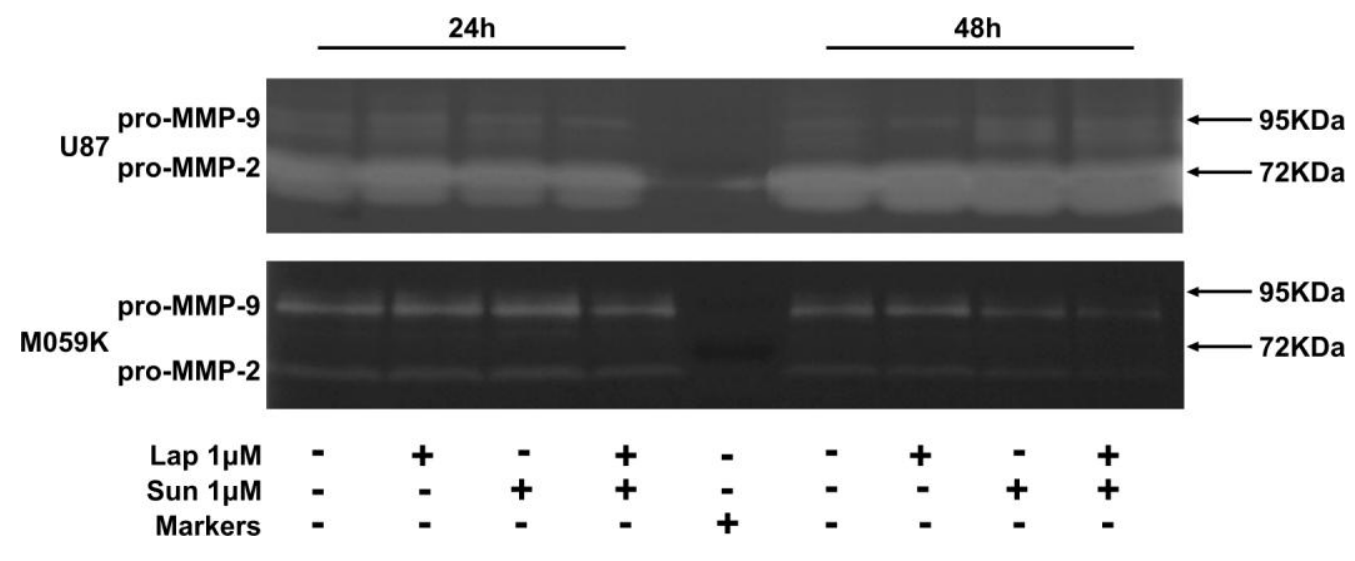

Figure 4: Effect of sunitinib and lapatinib on MMP-9 and MMP-2 secretion from U87 and M059K cells. This picture is a representative gel of three independent experiments. 